\title{
Comparison of the Polymerization Shrinkage of Eclipse Resin for Prostheses with Conventional Acrylic Resins
}

\author{
Comparación de la Contracción de Polimerización de la Resina \\ Eclipse para Prótesis con Resinas Acrílicas Convencionales
}

\author{
Maricela Vallejo-Labrada \& Luis Carlos Ocampo Benavides
}

\begin{abstract}
VALLEJO-LABRADA, M. \& OCAMPO, B. L. C. Comparison of the polymerization shrinkage of Eclipse resin for prostheses with conventional acrylic resins. Int. J. Odontostomat., 13(3):279-286, 2019.

ABSTRACT: The objective of this study was to compare the polymerization shrinkage of Eclipse photopolymerization resin for prosthesis based on urethane dimethacrylate (UDMA) with that of three heat-cured acrylic resins based on polymethyl methacrylate (PMMA) after the polymerization process and immersion in water. A total of 40 prostheses were fabricated on a standard metallic upper edentulous model: group 1, Eclipse; group 2, Triplex hot; group 3, Veracril; and group 4, Lucitone 199. Subsequently, the polymerization contraction was tested using a microscope in which measurements were made in micrometres at 3 points located in the middle parts of the right and left sides and the middle part of the palate at three time points once the prosthesis was completed, after 30 days of immersion in water for 8 hours a day at a temperature of $37{ }^{\circ} \mathrm{C}$, and after cutting the prosthesis at the level of the second premolar. ANOVA revealed that the contraction of the polymerization no statistically significant differences between the groups, $(P>0.05)$. The type of resin and its interaction with the processing method behaves similarly for all test resins. The Veracril heat-cured resin obtained the lowest contraction value in the three measurements $(\mathrm{mm})$ and the highest value was obtained with the Eclipse photopolymerization resin. The Eclipse resin exhibited no lower polymerization shrinkage compared to conventional acrylic resins based on polymethyl methacrylate (PMMA), however it was not significantly affected by immersion in water.
\end{abstract}

KEY WORDS: polymerization shrinkage, acrylic resins, denture base, Eclipse, urethane dimethacrylate.

\section{INTRODUCTION}

Most complete maxillary dentures do not precisely fit the mould due to changes in the resin during polymerization. The amount of heat associated with the processing of the polymethyl is correlated with the adaptation of the processed prosthesis base to its support tissues (Passam et al., 2012).

Despite improvements in the properties of acrylic resin, the problem of undesirable dimensional contraction remains unresolved (Firtell et al., 1981). Polymethyl methacrylate is the material of choice for prosthetic bases; however, dimensional changes of acrylic resins are inevitable, which is caused by the contraction in processing and expansion after water absorption (Skinner \& Cooper, 1943).

Advances in polymer science have led to new techniques, including a new denture base material free of methyl methacrylate (Eclipse) introduced by Dentsply Trubyte, York, PA. The chemical composition of this material, according to the manufacturer, is based on urethane dimethacrylate (UDMA), acrylated urethane oligomer, octadecyl acrylate, hexanediol dimethacrylate, and photoinitiators. This system is composed of three types of resins: a baseplate resin, a setup resin and a contour resin. The purported advantages include a lack of residual methyl methacrylate monomer; ease of manipulation; and elimination of the time-consuming procedures of waxing, investing, and wax elimination. The manufacturer also claims increased dimensional accuracy compared with conventional heatpolymerized resins (Artopoulos et al., 2013).

The objective of the study was to compare the polymerization shrinkage of three acrylic resins based

Facultad de Odontología Universidad Cooperativa de Colombia, San Juan de Pasto Nariño, Colombia. 
on polymethyl methacrylate and the Eclipse resin based on urethane oligomer to identify any significant differences according to the manufacturing process and after immersion in water.

\section{MATERIAL AND METHOD}

An in vitro experimental study was carried out, where 4 types of acrylic resin were compared; Group 1 Eclipse ${ }^{\circledR}$ resin (Denstply), group 2 Triplex hot $\circledast$


Lucitone ${ }^{\circledR} 199$ (Denstply). The laboratory process for the manufacture of the prosthesis was made in the preclinical area of the dentistry faculty of the Cooperativa de Colombia University and the measurements were made in the engineering laboratory of the University of Nariño.

A total of 40 prostheses were manufactured and divided into each group ( $n=10$ per group). All the prostheses were manufactured using plaster casts reproduced from a bronze metallic model obtained from an upper edentulous patient with a well-rounded halfalveolar ridge with no undercut, medium palate depth, and non-pronounced tuberosity (Fig. 1), for which three guides were made for assembly: two located on the side and one on the front to standardize the silicone matrices. All the prostheses were made under the same parameters and by the same operator.

On the obtained models, base plates stabilized in Triad Denture Base Sheet (Dentsply) were elaborated. Artificial Biodent acrylic teeth (New Stetic) colour A2, reference A25 for anterior and posterior teeth $31 \mathrm{~L}$ of 20 degrees in relation to a horizontal reference plane were set. Once aligned, was performed the conventional flasking method for groups 2, 3 and 4, in a Hanau curing unit (Hanau Engineering Company Inc., Buffalo, NY) using type II gypsum for the flask and gypsum type III (Whip Mix ${ }^{\circledR}$ ) for the countermuff following the manufacturer's instructions. Subsequently, dewaxing was performed and for the acrylation process, the manufacturer's specific recommendations were followed using a stove via immersion in water and controlling the temperature for each of the groups (Table I).

Group 1: Eclipse® resin (Dentsply, York, PA, USA). The prostheses were manufactured only from the baseplate resin and the setup resin for standardization purposes. All the faces of the teeth aligned were

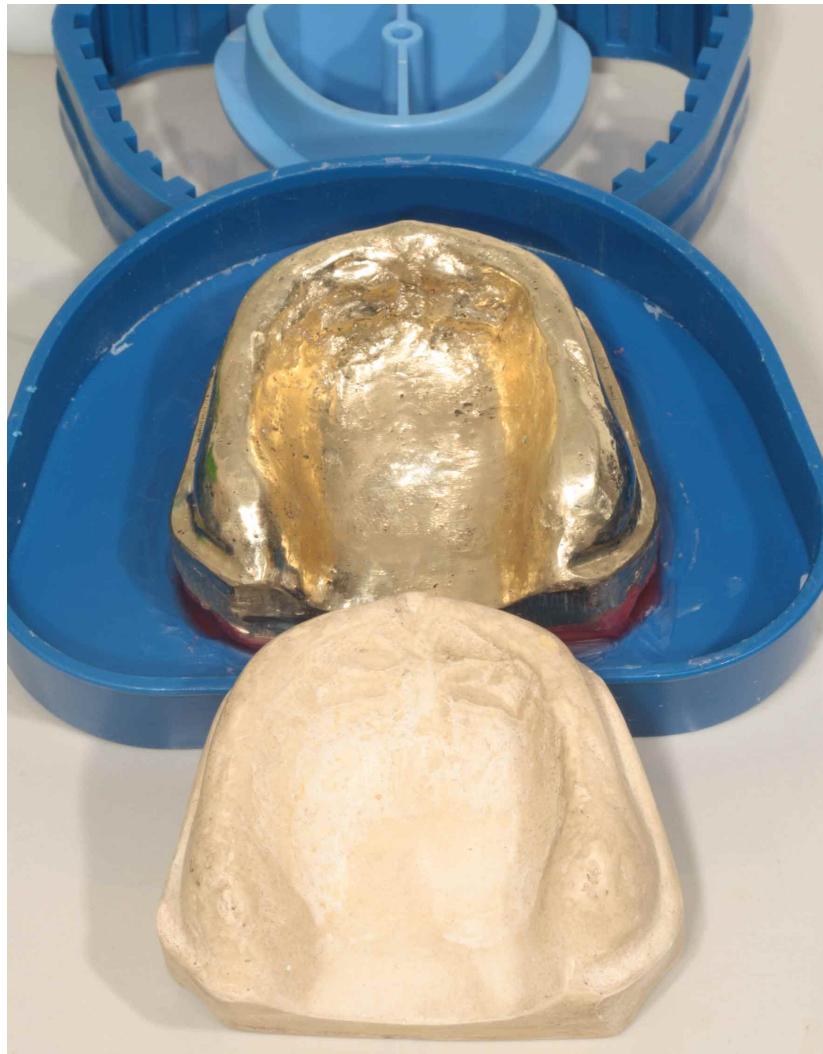

Fig. 1. Standardized metallic model.

thoroughly cleaned, and the interproximal spaces were accentuated. A matrix with laboratory silicone (Dentsply DeguDent Matrix putty) was developed. Once the precision of the teeth in the matrix was verified, any wax that may be left of the enamel was washed away completely. An Alcote separator layer (Dentsply) was applied to the cold dry model. The model was introduced into the incubator at $54{ }^{\circ} \mathrm{C}$ for 10 minutes. A new layer of Alcote separator was applied and left to dry. Photopolymerization was performed with the Eclipse Polymerization (EPL) unit of the Eclipse system using the programs indicated for each material. Once the characterization was complete, each model was introduced in the incubator at $54{ }^{\circ} \mathrm{C}$ for one hour for homogenization of the material. Then, the layer inhibitor (ABC) was applied. Once the polymerization was completed, the prosthesis was recovered. The prosthesis was immersed in water for 10 minutes, finished and polished to achieve the final gloss. Subsequently, we placed the inhibitor $(A B C)$ in the internal portion of the prosthesis, and the prosthesis was light-cured again.

After the polymerization, the prostheses were cooled to room temperature and subsequently remo- 
Table I. Description of the materials for the base of the denture.

\begin{tabular}{|c|c|c|c|c|c|}
\hline Group & $\begin{array}{l}\text { Trade name, } \\
\text { Manufacturer }\end{array}$ & Functional particle & Polymerization & Processing temperature & Processing time \\
\hline 1 & $\begin{array}{l}\text { Eclipse resin, } \\
\text { Dentsply }\end{array}$ & Urethane Oligomers. & Photopolymerization & $\begin{array}{l}\text { Starts at room } \\
\text { temperature up to } 140 \\
{ }^{\circ} \mathrm{C}\end{array}$ & $10 \mathrm{~min}$. \\
\hline 2 & $\begin{array}{l}\text { Triplex hot } \\
\text { Ivoclar Vivadent }\end{array}$ & $\begin{array}{l}\text { Polymethylmethacrylat } \\
\text { e PMMA }\end{array}$ & Thermopolymerization & $\begin{array}{l}\text { Starts at room } \mathrm{T}^{\circ} .100 \\
{ }^{\circ} \mathrm{C}\end{array}$ & $45 \mathrm{~min}$. \\
\hline 3 & $\begin{array}{l}\text { Veracril, New } \\
\text { Stetic. }\end{array}$ & $\begin{array}{l}\text { Polymethylmethacrylat } \\
\text { e PMMA }\end{array}$ & Thermopolymerization & $\begin{array}{l}\text { Starts at room } \\
\text { temperature up to } 73^{\circ} \mathrm{C} \text {. } \\
100^{\circ} \mathrm{C}\end{array}$ & $\begin{array}{l}90 \mathrm{~min} . \\
30 \mathrm{~min} .\end{array}$ \\
\hline 4 & $\begin{array}{l}\text { Lucitone } 199 \\
\text { Dentsply }\end{array}$ & $\begin{array}{l}\text { Polymethylmethacrylat } \\
\text { e PMMA. }\end{array}$ & Thermopolymerization & $\begin{array}{l}73^{\circ} \mathrm{C} \\
100^{\circ} \mathrm{C} \\
\text { Room temperature } \\
16-27^{\circ} \mathrm{C}\end{array}$ & $\begin{array}{l}1.5 \mathrm{~h} \\
30 \mathrm{~min} . \\
30 \mathrm{~min} \\
15 \mathrm{~min} .\end{array}$ \\
\hline
\end{tabular}

ved from the muffle. The finishing and polishing of the prosthesis were performed until the final gloss was achieved.

Group 2: Triplex Hot (Ivoclar Vivadent). The method recommended by the manufacturer was applied as follows: introduce the closed muffle into cold water, heat to $100^{\circ} \mathrm{C}$ and let boil for 45 minutes.

Group 3: Veracril (New Stetic). The method recommended by the manufacturer was applied as follows: 1) Heat room temperature water up to $73{ }^{\circ} \mathrm{C}$ for 90 minutes. 2) Keep in water at $100{ }^{\circ} \mathrm{C}$ for 30 minutes. 3) Cool in air at $23^{\circ} \mathrm{C}$ for 30 minutes. 4) Cool in water for 15 minutes.

Group 4: Lucitone 199 (Dentsply). The method recommended by the manufacturer was followed: the closed container (locked compression press or clamp) was immersed in water at $73 \pm 1^{\circ} \mathrm{C}\left(163^{\circ} \pm 2 \mathrm{f}\right)$ for one and a half hours. Then, the container was submerged for half an hour in boiling water at $100{ }^{\circ} \mathrm{C}$. The temperature of the water was periodically assessed with a precision thermometer. The vessel was removed and cooled to room temperature for 30 minutes. Then, it was immersed in cold water $\left(16-27^{\circ} \mathrm{C}\right)$ for 15 minutes before de-muffling.

Measurements. Once the prostheses were recovered, they were placed on the metallic master model, and their adaptation was observed. All measurements were made by the same researcher, for which a silicone matrix was manufactured to locate the model in the same position to standardize the measurement.

Polymerization contraction was tested using a digital microscope (Scientific AmScope) in which measurements were made in micrometres at three points located in the middle parts of the alveolar ridge right and left and the middle part of the palate, determining the distance from the posterior edge of the prosthesis up to the corresponding limits in the metallic master model. The measurements were performed at three time points once the prosthesis was completed, after 30 days of immersion in water for 8 hours a day at a temperature of $37^{\circ} \mathrm{C}$ and after making a cross section at the level of the second premolar with a diamond disc (0.15 TX-Flex separating Disc Dentaurum) with a low speed piece.

The mean values of polymerization shrinkage and standard deviation were calculated for each group, and the data were analysed by unidirectional variance analysis (ANOVA) followed by theTukey-Kramer HSD post hoc test using the statistical software SPSS statistics version 23 at a $95 \%$ confidence level to determine the mean differences for each study group.

\section{RESULTS}

Table II presents the average percentages of the contraction changes of the groups studied. The postpolymerization contraction at the middle part of the palate was greater in all groups, with Lucitone 199 resin presenting the greatest changes. ANOVA revealed that the type of acrylic resin processing cycle is directly related to the contraction, which significantly affected the dimensions in all the samples $(P<0.05)$. However, although there is a difference in the values of the measurement of the space between the acrylic resin bases and the model, the difference is not statistically significant between the groups studied. The 
Table II. Descriptive First Measurement Post-polymerization contraction (mm).

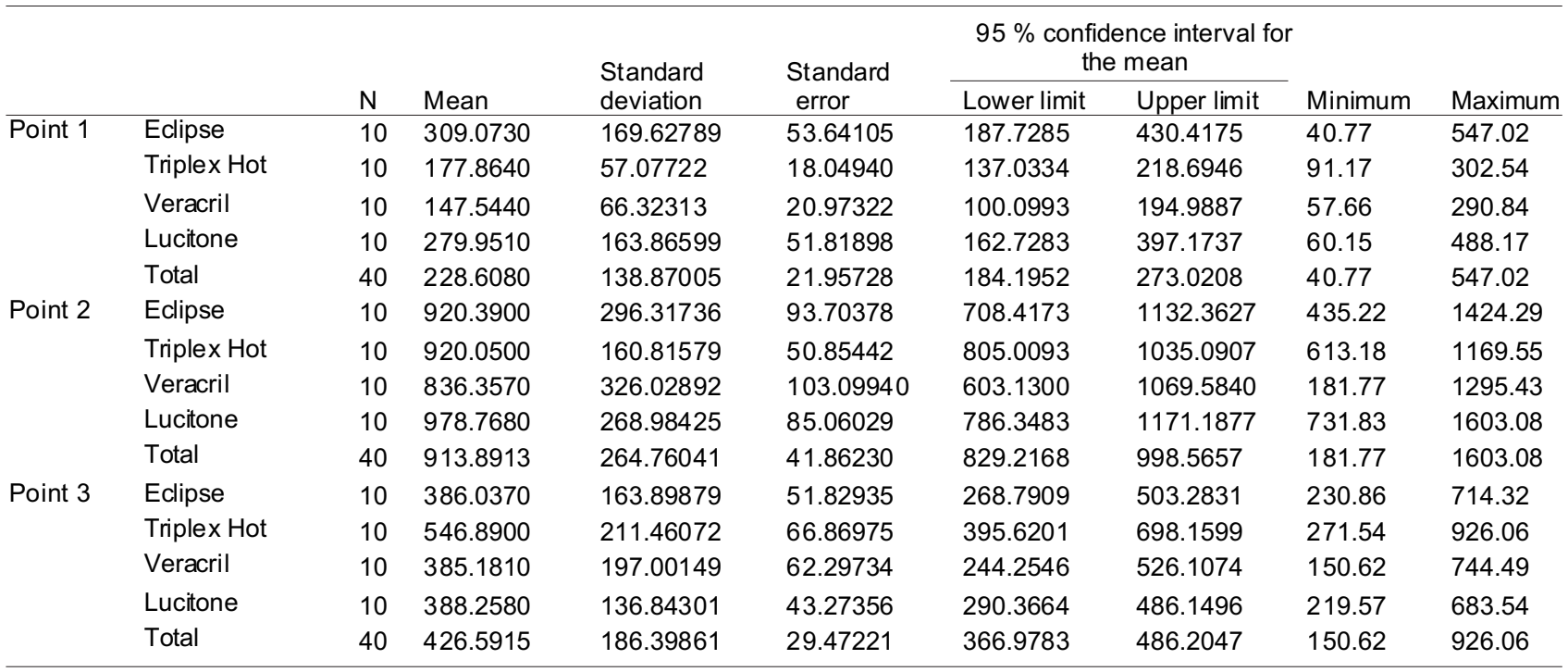

polymerization shrinkage and its interaction with the processing method were more effective for the Veracril thermopolymerization resin.

Tukey HSD revealed that the polymerization shrinkage of the Eclipse acrylic resin was not significantly different compared with the shrinkage produced by of acrylic thermopolymerization resins.

In the second measurement, after 30 days of immersion in water, statistically significant differences were found between the resins $(p \leq 0.05)$ (Figs. 2-5). The changes in the posterior seal are greatly reduced; all heat-cured specimens had a general tendency to increase linear measurements (expansion), probably due to water absorption (Akin et al., 2015). Conversely, greater contraction was observed, generating more space between the prosthetic base and the middle part of the palate in the acrylic resin Eclipse light-cured.

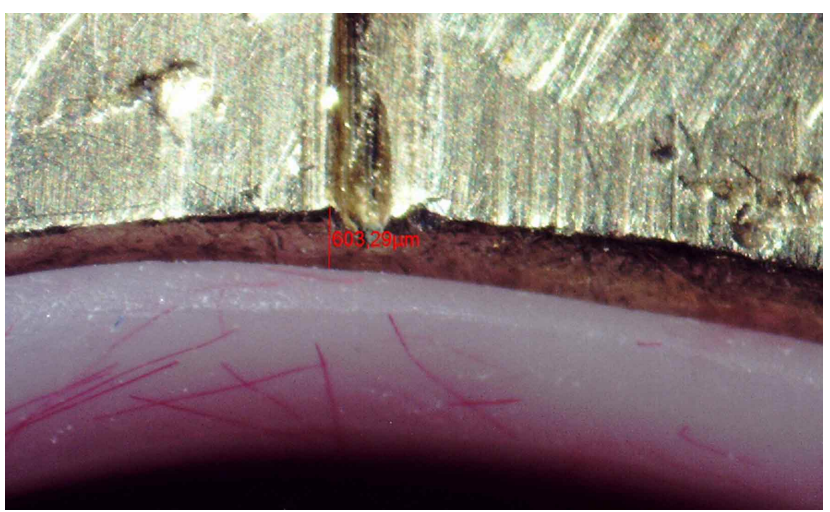

Fig. 2. Microscopic image acrylic resin Eclipse.



Fig. 3. Microscopic image acrylic resin Triplex hot.

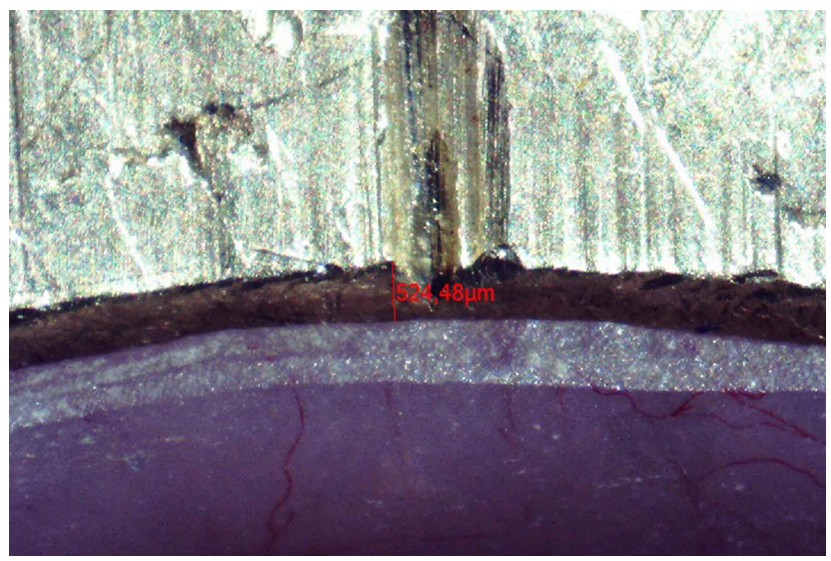

Fig. 4. Microscopic image acrylic resin Veracril.

In the third measurement, where a cross section was made at the level of the second premolar, a 


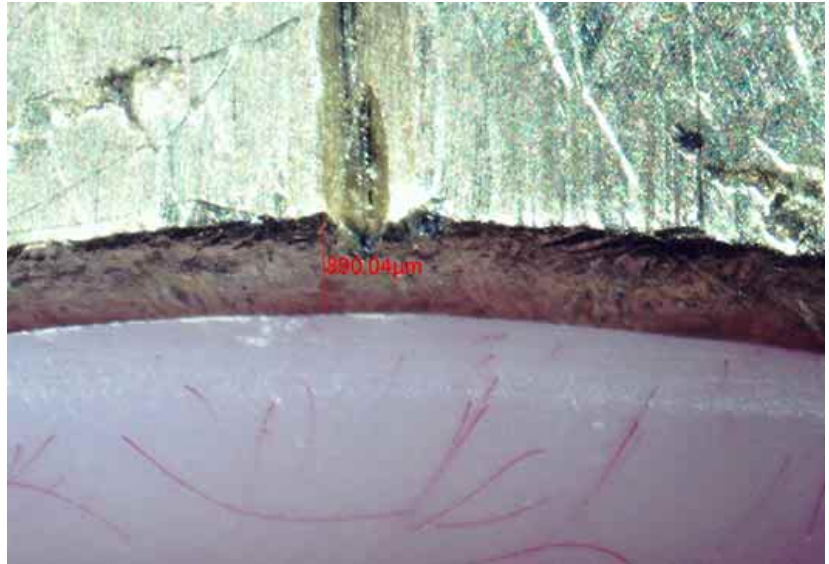

Fig. 5. Microscopic image acrylic resin Lucitone 199.

considerably smaller space is observed in all the samples in relation to the first and second measurement. The smaller space was exhibited by the Eclipse resin where the behavior improves in terms of the union of the prosthetic base to the model at that level, generating a greater adaptation (Table III).

Based on the result obtained, the Eclipse resin denture material does not exhibit lower polymerization contraction properties claimed by the manufacturers, compared with conventional acrylic resins.

\section{DISCUSSION}

Complete acrylic resin prostheses present certain inevitable dimensional changes. Shrinkage during processing and expansion due to water absorption are two important aspects that influence dimensional accuracy.

Most complete maxillary dentures do not precisely fit the cast due to changes in the resin during polymerization. This study verified that the base of the maxillary complete prosthesis exhibits the greatest discrepancy in the central part of the posterior palatal seal region as the temperature and processing time increase. This finding is consistent with that described by Pasam et al. (2012).

On the other hand, in the upper dentures, the maximum dimensional changes occur around the posterior segment (Abby et al., 2011). Other authors, such as Consani et al. (2002) reported in their study that the range of discrepancy between the bases of the maxillary prosthesis and the moulds was only 0.129 $0.286 \mathrm{~mm}$. The greatest average dimensional change was recorded in the posterior palatal area processed with the conventional packing technique. This finding is in contrast to the results obtained in our study in which three measurements were made and it is evident that the highest values of polymerization contraction occurred at the midpoint of the palate.

In addition, in the study conducted by Babu et al. (2016), concluded that in all fabricated prosthetic bases, the posterior palatal sealing area was the least dimensionally stable region and that denture bases fabricated using the long curing cycle would produce the most stable PMMA denture bases. However, in our study, the opposite happened: the lucitone resin that has the longest curing cycle showed greater dimensional change.

In the study by Fenlon et al. (2010), the maximum separation was 380 micrometres. The bases of the total prostheses were not significantly distorted as a result of undergoing a second thermal cure cycle as part of the final processing of the dentures.

High distortion of the denture bases has been reported when more than $72{ }^{\circ} \mathrm{C}$ have been used for processing (Passam et al., 2012), temperature that is indicated by the manufacturers for acrylic resins to achieve complete polymerization. In a study where the resins for PMMA prosthesis base were evaluated, the Lucitone 199 acrylic resin showed the highest values of linear dimensional changes compared to the other materials investigated. This material for denture base is a heat hardened acrylic resin and has the longest

Table III. Average dimensional changes of the test groups in the three measurements (midpoint of the palate).

\begin{tabular}{lcccc}
\hline Group & $\mathrm{N}$ & $\begin{array}{c}\text { First measurement } \\
\mu \mathrm{m}\end{array}$ & $\begin{array}{c}\text { Second } \\
\text { measurement } \mu \mathrm{m}\end{array}$ & $\begin{array}{c}\text { Third } \\
\text { measurement } \mu \mathrm{m}\end{array}$ \\
\hline Eclipse & 10 & 920.30 & 1021.11 & 146.23 \\
Triplex Hot & 10 & 920.05 & 774.69 & 250.50 \\
Veracril & 10 & 836.36 & 886.12 & 180.74 \\
Lucitone & 10 & 978.77 & 838.54 & 235.87 \\
\hline
\end{tabular}


curing cycle among the materials investigated, which could induce more conversion of monomers and, consequently, lead to dimensional changes (El Bahra et al., 2013). This situation is reflected with what was found in our study where this material obtained the highest values of polymerization shrinkage inside heat cured acrilyc resins.

In relation to water absorption, the findings of Mowery et al. (1958) do not confirm the results reported in the literature indicating that only immersion in water for 60 days could partially compensate for the contraction by polymerization. The water absorbed by the acrylic resin can act as a plasticizer and cause softening, discoloration (Consani et al.) and loss of mechanical properties of acrylic resin such as hardness, transverse strength and fatigue limit. However, water sorption causes three-dimensional expansion, and can affect the dimensional stability of acrylic resin (Babu et al.).

By comparing the dimensional changes of the samples processed by conventional techniques (SRIvocap Triplex Hot) and injection moulding (SR-Ivocap High Impact) and evaluating the dimensional accuracy after storage in distilled water at room temperature at intervals at 24 hours, 48 hours and 12 days using a digital calibrator, the acrylic samples produced by injection exhibited reduced dimensional changes compared with those produced by the conventional technique. probably the contraction of curing was compensated by the absorption of water (Gharechahi et al., 2014).

Denture base resins contract during curing and expand during storage in water. In our study, changes were observed after submerging the prosthesis for 30 days in water with the exception of eclipse light-curing resin. These findings were contradictory to the results obtained by Dixon et al. (1992) where no significant difference was observed in the linear dimensional change when acrylic resin was stored in water for 90 days probably due to the residual monomer, which prevents the absorption of water and maintains the dimensional stability of the base of the denture.

Apparently, the amount of absorbed water into heat-cured materials succeeded in releasing the residual stress emerged during curing (Lamb et al., 2005) and produce minimal an expansion which could improve the fit, probably attributed to the expansion phenomena (Braden, 1964) or/and less amount of inherent stress relaxation (McCabe \& Wilson, 1980).
Contrary in a more recent study deformation of the base of the prosthesis was observed through the use of 3D scanner and no obvious deformations were found in the group of water storage prostheses. However, in the dry-stored group, a typical deformation pattern was detected in the bilateral posterior area as time passes mainly in the first two weeks (Lim \& Lee, 2016).

There is little research on the Veracril resin, however, in one of them, they compared the dimensional changes of the polymerization by microwaves and thermopolymerization, where it was observed that the adaptation can be influenced by the activation mode, presenting dimensional changes; obtaining the highest values the acrylic Veracril (Soto Peña \& López Salgado, 2004). Contrary to what was observed in our study where it obtained less polymerization contraction in the three measurements, considered a relatively inexpensive material, with properties and characteristics necessary for used in the oral cavity and an acceptable adaptation capacity.

Alternative materials to PMMA have been used for the manufacture of denture bases (Machado et al., 2007). A resin polymerized by light, Eclipse (Dentsply Intl), baseded on urethane dimethacrylate (UDMA), with the following advantages: Absence of residual methyl methacrylate monomer, ease of handling, and the elimination of procedures that involve waxing time, investment and wax removal. The manufacturer also claims greater dimensional accuracy compared with conventional thermopolymerization resins. However, there is no evidence to support this claim in the current literature, and that it could be evidenced in our study where the polymerization shrinkage behaved in a similar manner as for conventional acrylic resins.

In a study carried out by Artopoulos et al., statistically significant differences were observed between the resin Eclipse $\AA$ and the PMMA-based resins in the deformations of the processing after the polymerization contraction. The resin based on urethane dimethacrylate exhibited increased processing deformation compared with resins based on polymethyl methacrylate. This finding contradicts the claims of improved dimensional accuracy for materials polymerized by light and is consistent with what was found in our study.

The bases of polymethyl methacrylate (PMMA) prostheses are deformed during polymerization, cooling and finishing. The cumulative 
effect of this deformation has been estimated to be between $0.45 \%$ and $0.55 \%$ linearly (Yeung et al., 1995; Wong et al., 1999). This deformation can affect retention because a close fit between the base of the prosthesis and the mucosa is essential for complete retention of the prosthesis.

Despite the development of different base materials of the prosthesis, acrylic resins remain the material of choice. The dimensional changes of the acrylic resins termopolymerized occur due to the thermal expansion by heating, shrinkage by cooling, shrinkage by polymerization and expansion as a result of water absorption. These variables can be controlled but not completely eliminated (Keenan et al., 2003).

The processed resins investigated showed dimensional changes, measured linearly in the posterior and middle palatine area and in the area of the tuberosity, after curing and after immersion in water, which may be clinically relevant and affect retention, stability and patient comfort.

\section{CONCLUSIONS}

The four experimental groups showed a general tendency to contract during their processing, however, the claims of lower polymerization shrinkage were not confirmed with the use of a light-curing resin based on UDMA. Patterns of deformation during the processing of acrylic resin definitive denture bases are complex cannot be fully analyzed by linear measurements alone.

VALLEJO-LABRADA, M. \& OCAMPO, B. L. C. Comparación de la contracción de polimerización de la resina Eclipse para prótesis con resinas acrílicas convencionales. Int. J. Odontostomat., 13(3):279-286, 2019.

RESUMEN: El objetivo de este estudio fue comparar la contracción de polimerización de la resina de fotopolimerización Eclipse para prótesis basadas en dimetacrilato de uretano (UDMA) con la de tres resinas acrílicas curadas con calor a base de polimetacrilato de metilo (PMMA) después del proceso de polimerización e inmersión en agua. Se fabricaron un total de 40 prótesis en un modelo edéntulo superior metálico estándar: grupo 1, Eclipse; grupo 2, triplex caliente; grupo 3, veracril; y grupo 4, Lucitone 199. Posteriormente, la contracción de la polimerización se probó utilizando un microscopio en el que se realizaron mediciones en micrometros en 3 puntos ubi- cados en las partes medias de los lados derecho e izquierdo y la parte media del paladar en tres puntos de tiempo una vez la prótesis se completó, después de 30 días de inmersión en agua durante 8 horas al día a una temperatura de 37 ${ }^{\circ} \mathrm{C}$, y después de cortar la prótesis a nivel del segundo premolar. ANOVA reveló que la contracción de la polimerización no presenta diferencias estadísticamente significativas entre los grupos, $(P>0,05)$. El tipo de resina y su interacción con el método de procesamiento se comportan de manera similar para todas las resinas de prueba. La resina curada con calor Veracril obtuvo el valor de contracción más bajo en las tres mediciones $(\mathrm{mm})$ y el valor más alto se obtuvo con la resina de fotopolimerización Eclipse. La resina Eclipse no mostró una contracción de polimerización menor en comparación con las resinas acrílicas convencionales basadas en polimetilmetacrilato (PMMA), sin embargo, no se vio afectada significativamente por la inmersión en agua.

PALABRAS CLAVE: contracción de polimerización, resinas acrílicas, base de prótesis, Eclipse, dimetacrilato de uretano.

\section{REFERENCES}

Abby, A.; Kumar, R.; Shibu, J. \& Chakravarthy, R. Comparison of the linear dimensional accuracy of denture bases cured the by conventional method and by the new press technique. Indian J. Dent. Res., 22(2):200-4, 2011.

Akin, H.; Tugut, F. \& Polat, Z. A. In vitro comparison of the cytotoxicity and water sorption of two different denture base systems. J. Prosthodont., 24(2):152-5, 2015.

Artopoulos, A.; Juszczyk, A. S.; Rodriguez, J. M.; Clark, R. K. \& Radford, D. R. Three-dimensional processing deformation of three denture base materials. J. Prosthet. Dent., 110(6):481-7, 2013.

Babu, S.; Manjunath, S. \& Vajawat, M. Effect of palatal form on movement of teeth during processing of complete denture prosthesis: An in-vitro study. Contemp. Clin. Dent., 7(1):36-40, 2016.

Braden, M. The absorption of water by acrylic resins and other materials. J. Prosthet. Dent., 14(2):307-16, 1964.

Consani, R. L.; Domitti, S. S. \& Consani, S. Effect of a new tension system, used in acrylic resin flasking, on the dimensional stability of denture bases. J. Prosthet. Dent., 88(3):285-9, 2002.

Dixon, D. L.; Breeding, L. C. \& Ekstrand, K. G. Linear dimensional variability of three denture base resins after processing and in water storage. J. Prosthet. Dent., 68(1):196-200, 1992.

El Bahra, S.; Ludwig, K.; Samran, A.; Freitag-Wolf, S. \& Kern, M. Linear and volumetric dimensional changes of injection-molded PMMA denture base resins. Dent. Mater., 29(11):1091-7, 2013.

Fenlon, M. R.; Juszczyk, A. S.; Rodriguez, J. M. \& Curtis, R. V. Dimensional stability of complete denture permanent acrylic resin denture bases; A comparison of dimensions before and after a second curing cycle. Eur. J. Prosthodont. Restor. Dent., 18(1):338, 2010.

Firtell, D. N.; Green, A. J. \& Elahi, J. M. Posterior peripheral seal distortion related to processing temperature. J. Prosthet. Dent., 45(6):598-601, 1981.

Gharechahi, J.; Asadzadeh, N.; Shahabian, F. \& Gharechahi, M. Dimensional changes of acrylic resin denture bases: conventional 
versus injection-molding technique. J. Dent. (Tehran), 11(4):398405, 2014.

Keenan, P. L.; Radford, D. R. \& Clark, R. K. Dimensional change in complete dentures fabricated by injection molding and microwave processing. J. Prosthet. Dent., 89(1):37-44, 2003.

Lamb, D. J.; Samara, R. \& Johnson, A. Palatal discrepancies and postdams. J. Oral Rehabil., 32(3):188-92, 2005.

Lim, S. R. \& Lee, J. S. Three dimensional deformation of dry-stored complete denture base at room temperature. J. Adv. Prosthodont., 8(4):296-303, 2016.

Machado, C.; Sanchez, E.; Azer, S. S. \& Uribe, J. M. Comparative study of the transverse strength of three denture base materials. J. Dent., 35(12):930-3, 2007.

McCabe, J. F. \& Wilson, H. J. The use of differential scanning calorimetry for the evaluation of dental materials. Part II. Denture base materials. J. Oral. Rehabil., 7(3):235-43, 1980.

Mowery, W. E.; Burns, C. L.; Dickson, G. \& Sweeney, W. T. Dimensional stability of denture base resins. J. Am. Dent. Assoc., 57(3):345-53, 1958.

Pasam, N.; Hallikerimath, R. B.; Arora, A. \& Gilra, S. Effect of different curing temperatures on the distortion at the posterior peripheral seal: an in vitro study. Indian. J. Dent. Res., 23(3):301-4, 2012.

Skinner, E. W. \& Cooper, E. N. Physical properties of denture resins: Part I. Curing shrinkage and water sorption. J. Am. Dent. Assoc., 30(23):1845-52, 1943.

Soto Peña, J. M. \& López Salgado, A. Comparación de cambios dimensionales en bases protésicas de acrílicos curados por calor y microondas. Rev. Odontol. Mex., 8(1-2):10-6, 2004.

Wong, D. M.; Cheng, L. Y.; Chow, T. W. \& Clark, R. K. Effect of processing method on the dimensional accuracy and water sorption of acrylic resin dentures. J. Prosthet. Dent., 81(3):3004, 1999.

Yeung, K. C.; Chow, T. W. \& Clark, R. K. F. Temperature and dimensional changes in the two-stage processing technique for complete dentures. J. Dent., 23(4):245-53, 1995.
Corresponding author:

Maricela Vallejo-Labrada

Facultad de Odontología

Universidad Cooperativa de Colombia

San Juan de Pasto

Nariño

COLOMBIA

Email: maricela.vallejo@campusucc.edu.co

Received: 19-02-2019

Accepted: 17-04-2019 